\title{
Measuring and modelling the spatial accessibility of public transport stops in GIS
}

\author{
STANISLAV KRAFT ${ }^{1}$
}

\begin{abstract}
This article introduces two basic exact approaches for evaluation of spatial accessibility of public transport stops in the geographical information systems environment. The first is considered to be a simple approach contributing to the definition of buffers (wrap zones) around the stops. These are based on geometrical concept and use simple euclidean distance for specification of coverage of the individual city quarters. The present study works with the distance of 400 metres, which in the urban environment represents a comfortably accessible walking distance of 5 minutes. The other approach (the isoline method) is already considered to be more advanced, as it is based on the sophisticated tools of geographic information systems, which are able to interconnect the existing access paths and take the individual spatial barriers into consideration. This results in a realistic image of public transport stop accessibility already fully corresponding to the real situation. This tool may not only be used for current status analysis, but also for future status prediction. The example of establishment of new stops in the city of České Budějovice, therefore, uses this instrument for determining the impact of the new stop establishment in the city centre on the city coverage.
\end{abstract}

Keywords: public transport, accessibility, transport planning, GIS

\section{Introduction}

In the past two decades modern geo-information technologies have visibly invaded the field of transport. Their utilisation in transport processes is rather broad and complex. Good examples include, for instance, smart traffic systems, GPS navigation, automatic control of logistic centres, etc. The purpose of their use in transport is to make transport safer, more fluent and more effective. Although modern geo-information technologies are today a virtually indispensable component of transport management, they are still very sparingly used in transport planning (Mintsis, G. et al. 2004). This is specifically manifested in public transport planning where accurate geographical information is often missing. Public transport is therefore often planned without use of these modern geo-information technologies, which may negatively affect their competitive position on the transport market.
This article tries to point out the benefits of using geo-information technologies with the help of the example of measurement and modelling the accessibility of public transport stops in the geographical information systems (GIS) environment. Basic approaches to measurement and modelling the accessibility of public transport stops are introduced, and their often completely different results are declared. The approaches to measurement and modelling public transport stop accessibility are applied to the city of České Budějovice in the Czech Republic, in the form of a case study. Two different methods of stop accessibility measurement and modelling are used and their results are compared. The present article also shows the benefits of utilisation of geographically accurate information in this area.

Our motivation to study this issue springs from experience in public transport planning, especially in cities within the Czech

\footnotetext{
${ }^{1}$ Department of Geography, University of South Bohemia in České Budějovice. Jeronýmova 10, 37115 České Budějovice, Czech Republic. E-mail: kraft@pf.jcu.cz
} 
Republic. These modern research methods are in fact very rarely applied in practice. On the other hand, less sophisticated procedures (approximations), which are today hardly able to fully reflect the complex demands in transport, are relatively frequently used. The results of the present study are, therefore, not only highly relevant for transport research but also, and above all, for practice. The application scope of the methodological procedures described here is therefore primarily seen in the conceptual planning of city transport. Spatial accessibility of public transport stops is perceived as one of the key characteristics with direct impact on the quality and utilisation of public transport in cities (see Cervero, R. 2001; Beirão, G. and Cabral, J. 2007).

The structure of the article is as follows: after the introductory chapter there is a presentation of a theoretical framework of traffic stop accessibility, public transport and mobility in urban regions in general. Attention will be focused on current approaches to these issues and their reflections in professional literature. The following chapters will introduce two basic and most frequently used methods of modelling and measurement of public transport stop accessibility in urban environments. While one of them is a simple method using approximate input information, the other is an advanced and relatively highly accurate method based on analysis of precisely localised spatial information and sophisticated GIS based procedures. The analytical part of the study applies both approaches to the model territory of the city of České Budějovice on a very detailed level. The final part then synthesises the results into recommendations for transport planning and suggestions of further research themes.

\section{Theoretical background}

In recent years research focus has returned to public transport. In agreement with the findings of MavoA, S. et al. (2012) we can see causes of this increased interest in several aspects.
Firstly, public transport has entered a period of renaissance in many European countries for its lower environmental burden in comparison to automobile transport. Benefits of public in comparison to individual transport not only include the reduction of direct traffic burden represented by emissions, but also more effective energy consumption, reduced traffic accident rates, less traffic congestion and lower demands on physical activity. And last but not least, public transport positively contributes to social integration (KENYON, S. et al. 2002). Another substantial factor causing the increased interest in public transport is the fact that public transport is often the only available transport mode for a large group of citizens, who for some reason cannot use passenger cars (see the discussion in Sheller, M. and Urry, J. 2006, or Cebollada, A. 2009). This group primarily includes the handicapped, children, seniors, etc. Due to the demographic aspect of an ageing population, especially in advanced countries, the percentage of this population group may be expected to increase (KÁčERová, M. et al. 2014). Public transport is, therefore, one of the key factors affecting the sustainable development of mobility for this substantial part of the population. As it is also an important aspect of life quality, public transport deserves proper attention.

This is why public transport currently maintains a relatively stable position in competition with individual automobile transport after a considerable decrease of transport outputs in the 1980s and 1990s. In the Czech Republic, like in many other countries, the benefits of public transport are beginning to surface, especially in big cities and metropolitan areas. A continuous increase of city transport since the mid-1990s can be documented. Public transport in cities offers a number of advantages, which make it competitive in relation to individual automobile transport (frequent use of reserved traffic lanes, speed, absence of problems with parking etc.). If public transport is to successfully compete with passenger cars in cities, it clearly must offer adequate services and 
complex and flexible reactions to traffic demand. Cities and metropolitan regions generate a high level of demand for transport. In addition, cities and urban systems are currently characterised by considerable changes in their spatial arrangements. This is related to the onset of the post-industrial patterns of city layouts with a typically complicated arrangement of land use in the city, development of residential and non-residential suburbs, outflow of population from city centres etc. (Burchell, R. et al. 1998; Džupinová, E. 2009; Temelová, J. et al. 2011). The formerly relatively simple concentric patterns of transport relations in cities are today replaced by more complex traffic structures. Population numbers in individual city quarters change dynamically together with the changing functions of the quarters, temporal and spatial mobility rhythms, etc. Current transport behaviour and trends in personal mobility are therefore quite demanding and highly individual (Popov, V. 2012). Public transport is only able to react to these changes to a limited extent, which is shown by a number of studies on current population mobility and transport behaviour (e.g. KRAFT, S. 2014).

Accessibility of public transport has been one of the key attributes of its quality, which indirectly affects its competitiveness in relation to automobile transport. The advantages of automobile transport mainly lie in door-todoor transport (IvAN, I. 2010). On the general level accessibility may be characterised as the number of facilities (traffic terminals, stops etc.) available in a certain time or within a certain walking distance or for a certain charge. Pursuant to Michniak, D. (2010) accessibility comprises three relatively mutually independent elements - the subject of accessibility (a person, a group of persons, inhabitants of a certain region), the object of accessibility (a certain occasion, activity or service) and the transport element realising the connection between the subject and the object of accessibility helping to cover the distance between them. In this context one can speak about "dual" accessibility - accessibility of localities and accessibility for a certain person or group of persons.
What needs to be accessible on the level of cities and urban areas is the public transport stops expressed by walking distance from residential areas of the cities. Other forms of public transport stop accessibility (e.g. "Park and Ride") are mainly important in big cities. Residential quarters in this context represent the demand for transport services, while public transport stops and their locations represent the offer of transport services. For effective functioning of city transport it is necessary to find the best possible balance between this offer and demand. Accessibility of public transport stops may, therefore, primarily be monitored with consideration of their distribution and locations. The aim is maximum coverage of the urban space represented mainly by the permanent residents of the space. Growing relevance of public transport can also be documented by its impact in the surrounding environment. A number of studies point to a clearly direct relationship between the accessibility of public transport stops and the growing differentiation of land value. This is mainly visible in cities and in close proximity to main roads and railway lines (CErvero, R. and Duncan, M. 2002). Cervero and Kang, using Seoul as an example, show that measurable impact on land value may be seen in cases where a bus/tram stop is within 300 metres in the case of residential land use function, and without approximately 150 metres in the case of retail and other non-residential land use (CERvero, R. and KANG, C.D. 2011).

GIS represents one of the most frequently used instruments of analysis of the complex relationship of transport stop accessibility and city coverage with public transport. These systems, on the one hand, allow full use of very accurate geographical information, and on the other, creation of a sophisticated model of predictions of future status. The environment of geographical information systems provides a number of instruments for analysis of various levels of accessibility on all hierarchical levels. Their substantial relevance, however, consists not only in analysis of the existing reality, but 
also in theoretical modelling and predictions of changes of accessibility under the influence of interventions with the current system of transport infrastructure in particular, or more generally organisation of traffic processes in the territory (Ahmed, N. and Miller, H.J. 2007). For this reason in western countries GIS currently represent a standard part of transport planning and traffic control.

\section{Methodology}

The methodology of measurement and modelling public transport stop accessibility consists of several sequential steps. The basic source data necessary for further analyses is represented by precisely localised information about locations of individual public transport stops, line routes, the number of inhabitants of individual houses, layout of local public and service roads, and pavements and other accesses for pedestrians, etc. Although certain data was obtained from public databases, most of it had to be accumulated by in-house survey. A mobile GPS device was used to measure the precise positions of public transport stops in the city of České Budějovice. The data was subsequently transferred to the SJTSK coordinate system in GIS.

Data on the number of inhabitants of individual houses represents a valuable and very detailed source of field information necessary for the calculation of territorial coverage with public transport stops. Conversely, residents do not represent the only key attribute for the distribution of public transport stops. The resulting analyses, thus, do not include further important aspects of certain functions connected with daily intra-city mobility (schools, public institutions, healthcare facilities, shops, etc.). Despite that quantification of the results by means of the number of residents of individual houses represents a very substantial characteristic feature of city coverage with public transport stops, therefore, the obtained results can be considered relevant and conclusive. Data on the number of residents of individual houses was unfor- tunately only available for the inner city of České Budějovice (without the surrounding suburban villages). Therefore, analyses of spatial accessibility could only include data related to this city exclusive of all the municipalities served by Budějovice city transport. We also use estimates of potential users of public transport stops by quantifying the daily population (residential population plus working/studying population, tourists etc.) in specific cases. Although this approach is quite complicated, it clearly shows differences in use of specific public transport stops (especially near shopping centers far away from residential areas).

The evaluation methodology of spatial accessibility of public transport stops in the city of České Budějovice was developed with the help of extended Network Analyst and Spatial Analyst in ArcView 9.2 software. These instruments allow for the sophisticated expression of spatial accessibility of city transport stops by means of the buffer method (wrap zone method) and by means of specification of the isolines (method of connection of points in the same distance/travel time).

The research generally confirmed that threshold values for evaluation of public transport stop accessibility in urban regions generally range within 5 minutes walking distance, which represents a distance within 400 metres (e.g. Foda, M. and Osman, A. 2010; Adebola, O. and Enosko, O. 2012). The following analyses will, therefore, work with the comfortable variant of individual stop accessibility (within $5 \mathrm{~min}$ or $400 \mathrm{~m}$ walking distance). For the sake of simplicity all buildings outside this defined range of public transport stop accessibility were considered inaccessible. Individual results could be exactly quantified through the number of residents of the individual houses. The first testing method used was the simple buffer method (wrap zones). Buffers can be defined as concentric circles with the centres in the individual stop points defined by means of euclidean distance. Therefore, application of the buffer method produced circles around individual stops within the $400 \mathrm{~m}$ radius. 
The major methodological limitation of the buffer specification is the fact that the zones do not respect any environmental barriers (such as water works, road crossings, buildings, etc.). The results within our micro-scale are, therefore, greatly generalised and poorly correspond to the reality.

For that reason we used the other method of isolines, which may be defined as lines connecting points within the same spatial or temporal distance from the starting point. Advantages of the isolines include respecting all spatial barriers to distance coverage. This procedure may be considered more accurate, but logically is much more difficult. The methodological procedure consists of the precise connection of a network of local and service roads, networks of pavements and other pedestrian paths with public transport stops and individual buildings in the city of České Budějovice. The data layers were subsequently merged in ArcView 10.2 and subjected to accessibility analysis with the help of the "Service Area" function in the extended Network Analyst. This created a variant of spatial accessibility of public transport stops better corresponding to the real situation.

Expression of the spatial accessibility quality of the stops was assessed by means of coverage of buildings used for permanent residence by the local population. This allowed for the expression of the qualitative aspect of coverage of the area of interest with public transport stops, unlike the traditionally used coverage approximation with the help of the population density of individual city quarters (e.g. Murray, A.T. 2003). The extended Spatial Analyst and the "Select by location" tool helped us to express the spatial accessibility of public transport stops in the comfortable (within $400 \mathrm{~m}$ ) variant through the number of permanent residents. At the same time we defined localities in České Budějovice situated outside the comfortable variant of spatial accessibility of the stops. These problematic localities may become a stimulus for optimisation of this condition in the coming years. For better visualisation some of the problematic areas are shown in 3D maps.

\section{Results}

With a population of nearly 95,000 the city of České Budějovice is the biggest city in the South Bohemia region. The latest census revealed that more than 22,000 people additionally commute to the city every workday for work or school. Therefore, the real city population is nearly 120,000. Another substantial fact is that the city is relatively small in size. The cadastral area of the city is a mere $55 \mathrm{~km}^{2}$. The mean population density is more than 1,700 per $\mathrm{km}^{2}$. The highest population density is in the inner city and in the housing estates on the outskirts. Despite the compact housing, recent trends of commercial and residential suburbanisation manifest themselves here as well. All of the abovementioned specifics indicate a high demand placed on public transport.

The buffer method defined concentric circles in the territory of České Budějovice with their centres in all city transport system stops (Figure 1). At first sight the distribution of public transport stops across the city is relatively good. The stop distribution follows the locations with the highest concentrations of people, and therefore the highest demand for public transport. Due to this distribution the buffer method, thus, shows very favourable characteristics of individual building coverage with the system of stops. Stops within walking distance of up to $400 \mathrm{~m}$ are available to 56.9 percent of the residents within the territory. Buildings within the buffers are inhabited by 85,919 residents. These characteristics reveal very convenient coverage with public transport stops as 92.1 percent of the city population can enjoy comfortable public transport accessibility. The most favourable values are shown for the inner city, where the network of public transport lines and stops is the densest. In these localities the individual buffers often overlap. The coverage in the densely populated localities on the outskirts (housing estates), with high concentrations of people in small areas, is also favourable. The demand for public transport in these localities is very concentrated, which 


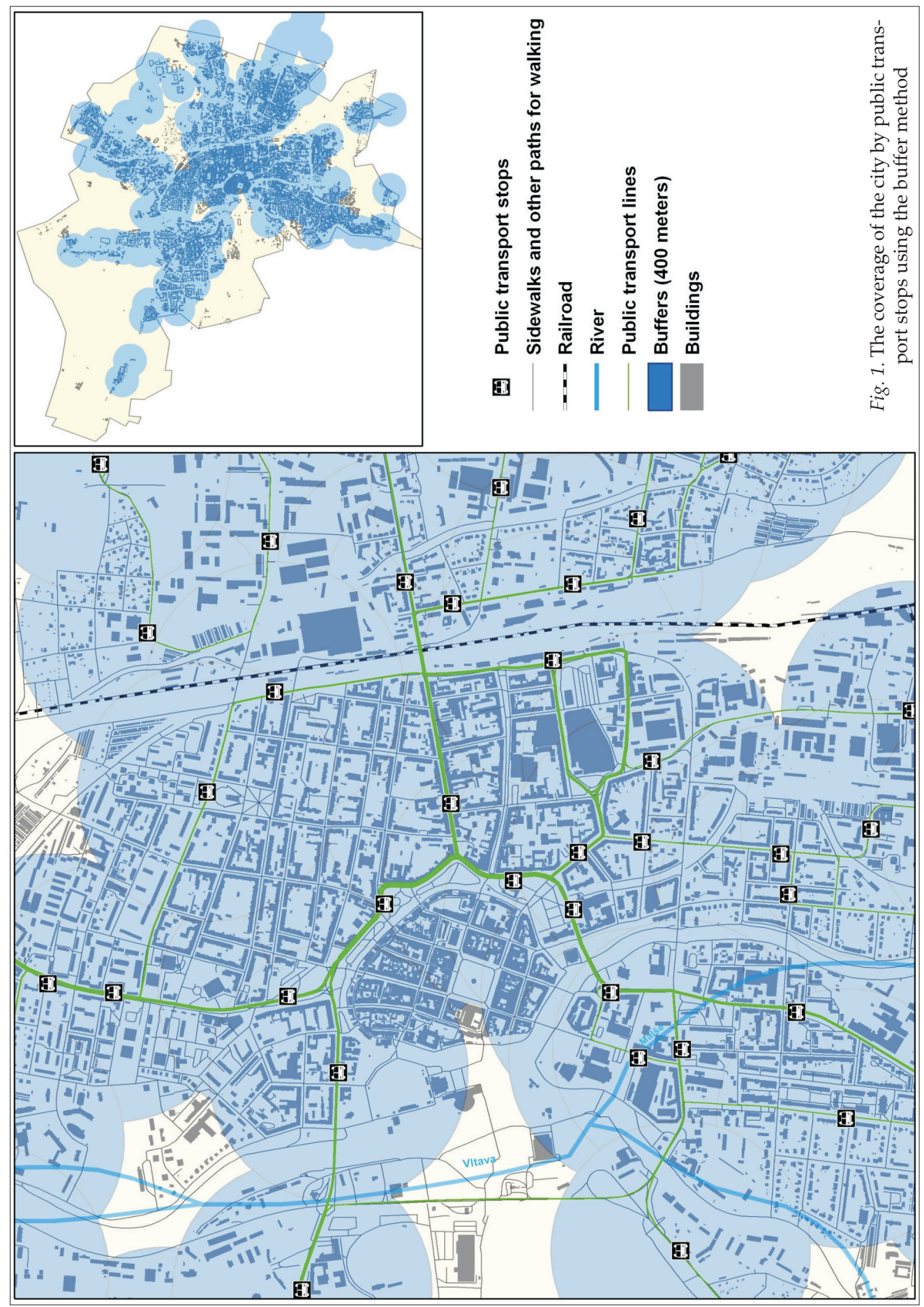


is an important factor for the offer of public transport services. On the other side, rather unfavourable coverage conditions are found at the outskirts with a lower population density and in industrial zones.

A different view of the issue is shown in Figure 2, which demonstrates that when the buffer method is used most city residents can use a conveniently accessible public transport stop. The limit of $400 \mathrm{~m}$ is only exceeded in the more remote localities with lower population density. The modus of the whole set is represented by the zone of buildings 120-140 metres away from the nearest stop which, according to the buffer method, is populated by nearly 8,500 citizens. The cumulative curve shows a relatively quick increase of population in the lowest values - 50 percent of the city residents live within 180 metres from the nearest public transport stop.

Despite these favourable characteristics the buffer method clearly provides overly generalised results, not considering any existing spatial barriers to public transport stop accessibility. This is shown by the more sophisticated expression of spatial accessibility of public transport stops by means of the advanced isoline method. Following

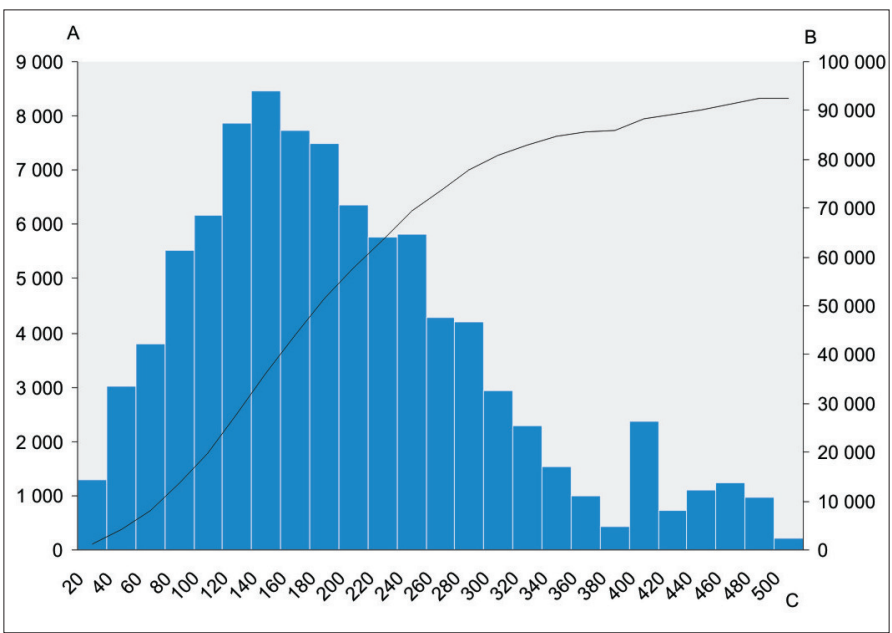

Fig. 2. Spatial distribution of residential population to the nearest public transport stop measured by the buffer method. $-\mathrm{A}=$ population in selected distance zones; $\mathrm{B}=$ cumulated population; $\mathrm{C}=$ distance to the nearest public transport stop (in meters) incorporation of all these barriers the resulting accessibility image fully corresponds to the reality. The individual accessibility zones are no longer regularly shaped, but they are plotted with regard to the real access options including all access types (pavements, paths, subways, street crossings etc.).

As shown by the drawn isolines 71,585 city residents (76.8\%) live within $400 \mathrm{~m}$ from the nearest public transport stop with the total coverage representing 44 percent of the city area. The lower values are logically caused by the more accurate specification of the accessibility zones. These are shown in Figure 3. They respect all existing spatial barriers. This is specifically manifested in the surroundings of rivers or railways representing significant barriers structuring the city in the north-south direction. These strong barriers may only be overcome in a couple of defined places, and thus, strongly influence the value of pedestrian accessibility of public transport stops in their proximity. A specific situation can be seen near the historic city centre. Although this part of the city shows a lower population density, there are important institutions situated there, such as banks, offices and shops, connected with the daily mobility of many of the city residents. As the public transport system bypasses the main square, their accessibility is limited. In addition in České Budějovice it is still easy to park a car in the square. This is one of the examples of the missing concept of public transport serving the city centre.

Spatial distribution of residents with regard to their access to the nearest public transport stop is not as favourable as in the previous case (Figure 4). This is again given by the more accurate calculation methodology considering the real options of access to the stop. 


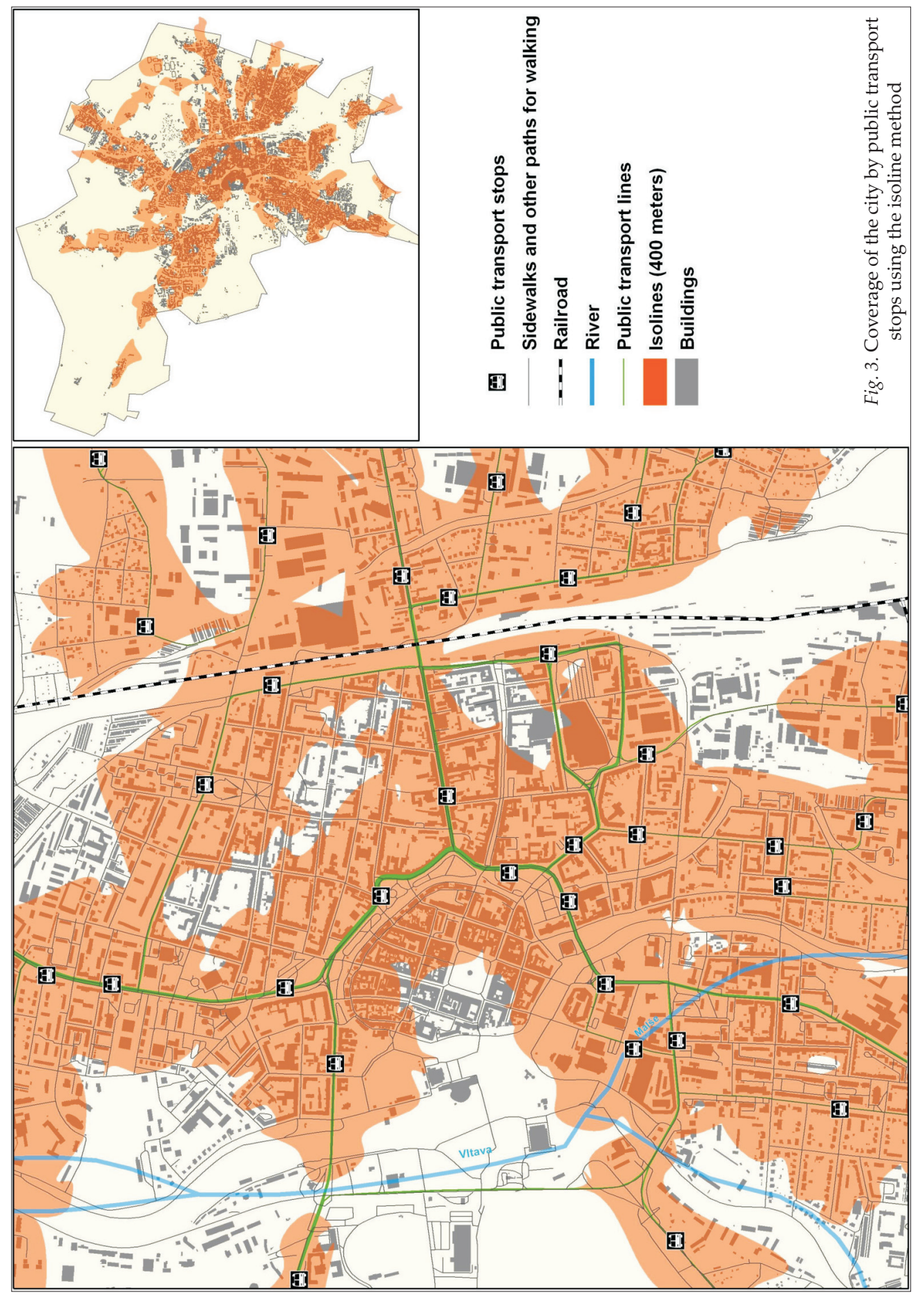


The general conclusion of this evaluation is that the real distance of the nearest stops is longer by order of dozens or hundreds of metres than shown by the previous method. The modus of the set is represented by the zone within 300-320 metres from the nearest stop, where over 6,500 city residents live. On the other hnad, behind the monitored frontier of 400 metres there are more residents than in the case of the previous method. The shape of the cumulative curve is more convex, which shows that the increase of the population with increasing distance is not as steep as suggested by the previous evaluation with the buffer method. Half of the city population live within a distance of up to 280 metres from the nearest public transport stop. Quantitative comparison of the two methods of coverage calculation by means of the buffer and the isoline methods is shown in Table 1.

We tried to calculate the real daily population to quantify the usage of particular public transport stops. This approach is quite complicated and questionable. For this reason we chose specific types of stops, which we con-

Table 1. Coverage of the city using the basic structural features

\begin{tabular}{l|c|c|c}
\hline Method & Area, $\mathrm{km}^{2}$ & Buildings & Inhabitants \\
\hline Buffer & 31.29 & 20,489 & 85,919 \\
Isoline & 24.37 & 16,446 & 71,585 \\
\hline
\end{tabular}

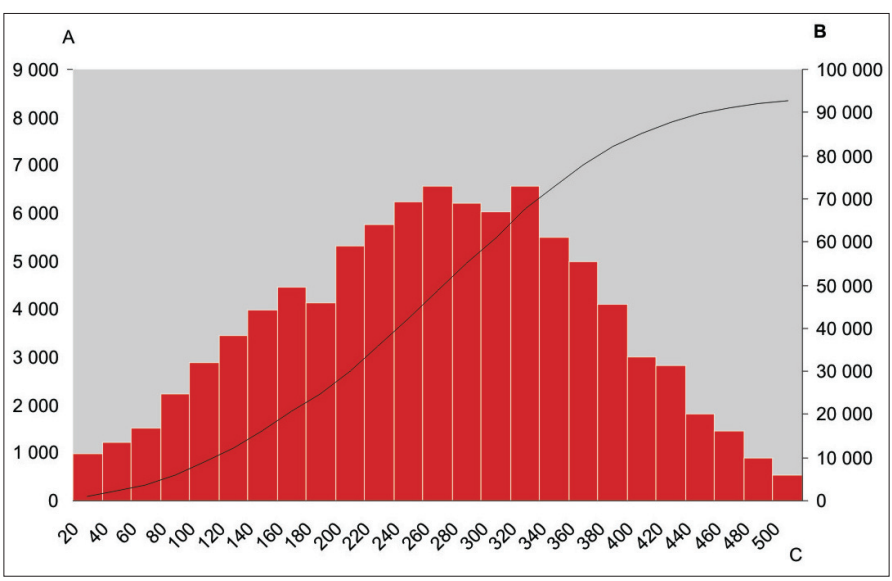

Fig. 4. Spatial distribution of residential population to the nearest public transport stop measured by the isoline method. - A, B, C = see Fig. 2. sidered as specific in the transport system of the city. We tried to estimate the real number of people who can use the public transport stop (similarly LANGFORD, M. and Higgs, G. 2006). The monitored stops were near the largest shopping centre (stop 'Globus'); near the university campus (stop 'Jihoceska univerzita') and near to the city hospital (stop 'U Nemocnice'). All stops are operated by the key trolleybus and bus lines. The goal of the research is to quantify the potential users of these stops. The results, thus, include the residential population, estimates of working/ studying people and number of daily visitors. The data were collected from accessible statistics, special statistics and also by field survey realised by the author. Although these data are estimated, we consider them as realistic (Table 2).

The results clearly show obvious differences among particular types of selected bus stops. The most important influencing factor is the functional structure of the affected area and geographical location. The greatest contrast is by the stop 'Globus', which is localised in the north-western part of the city, far away from most residential areas. Because of low residential population density there are only 47 residents in the accessible area. According to our calculations the number of potential daily users of the shopping center is over 14,000 people. This is the unique case. The other two stops are located in more densely populated areas nearer to the city centre. Their residential population is higher, but their working/ studying population (university) or other daily population (hospital) is usually several times higher. We suppose that similar values are also typical for other types of stops (main rail and bus stations, city square, exhibition grounds or cemetery). On the other hand, we think that these types of stops in 
Table 2. Potential users of selected public transport stops

\begin{tabular}{l|c|c|c|c}
\hline Name of transport stop & $\begin{array}{c}\text { Residential* } \\
\text { population }\end{array}$ & $\begin{array}{c}\text { Working/studying } \\
\text { population** }\end{array}$ & $\begin{array}{c}\text { Other daily } \\
\text { visitors** }\end{array}$ & Together \\
\hline Globus & 47 & 627 & 13,700 & 14,374 \\
Jihoceska univerzita & 1,689 & $1,047 / 5,970$ & $750 * * *$ & 9,456 \\
U Nemocnice & 1,373 & 2,530 & 2,800 & 6,703 \\
\hline
\end{tabular}

${ }^{*}$ Official statistical data; ${ }^{* *}$ Annual Reports of appropriate institutions; ${ }^{* *}$ Field survey conducted by the author.

the city are relatively small. The residential population is still in our opinion one of the most important features for analysing the spatial accessibility.

Current development strategy of public transport in České Budějovice counts with establishment of new public transport stops by 2020 . These stops should improve the existing conditions and the spatial accessibility of certain localities. New stops are planned around the historic city centre, inter alia. The isoline method allows for modelling of this status and prediction of the expected changes. This, however, faces the fact that the historic city centre has a relatively lowdensity population. Thus, the results of the accessibility change modelling will manifest themselves less here in the quantitative expression, for only a small number of people will probably move to the comfortable accessibility zone. On the other hand, as mentioned above, the city centre shows a considerable concentration of institutions related to the everyday mobility and activities of the citizens. It is, therefore, clear that establishment of new public transport stops will bring about the expected effects. That is why Figure 5 shows $3 \mathrm{D}$ visualisation of the current accessibility of the nearest public transport stops and model expression of the planned condition after establishment of new stops. The accessibility evaluation was again based on the isoline method reflecting the real accessibility by means of sophisticated use of the existing paths for pedestrian traffic.

Two new public transport stops in the historic city centre will add only 128 new free-standing buildings to the coverage with comfortable access, serving as a permanent residence to 142 persons (most of the newly added buildings are unoccupied). As already mentioned, this change will marginally change the number of people living in the zone of comfortable public transport accessibility. On the other hand, the new stops will cover part of the city with a significant concentration of important institutions (city magistrate, banks, city pool, restaurants etc.). Despite certain criticism the newly planned stops and public transport lines to the city centre may be said to be beneficial, making significant everyday life localities newly accessible to more persons having to rely on public transport.

\section{Conclusions}

The performed measurement and modelling of public transport stop accessibility analysis, taking the city of České Budějovice as an example, yielded certain results that might be generalised and used for further research. General findings include the fact that the monitored maximum distance from the nearest public transport stop correspond to 400 metres and 5-minute walking distance is the limit of acceptability, even for the studied city. The results of the intra-city space coverage survey were relatively good in both cases, with only localities with a very low population density situated behind the $400 \mathrm{~m}$ boundary. Hence the threshold of $400 \mathrm{~m}$ from the nearest stop may be declared sufficient.

The abovementioned accessibility evaluations can be summarised as follows. First, empirical assessment of spatial accessibility of public transport stops in the city of České Budějovice by means of both buffer and isoline methods showed that the stop 


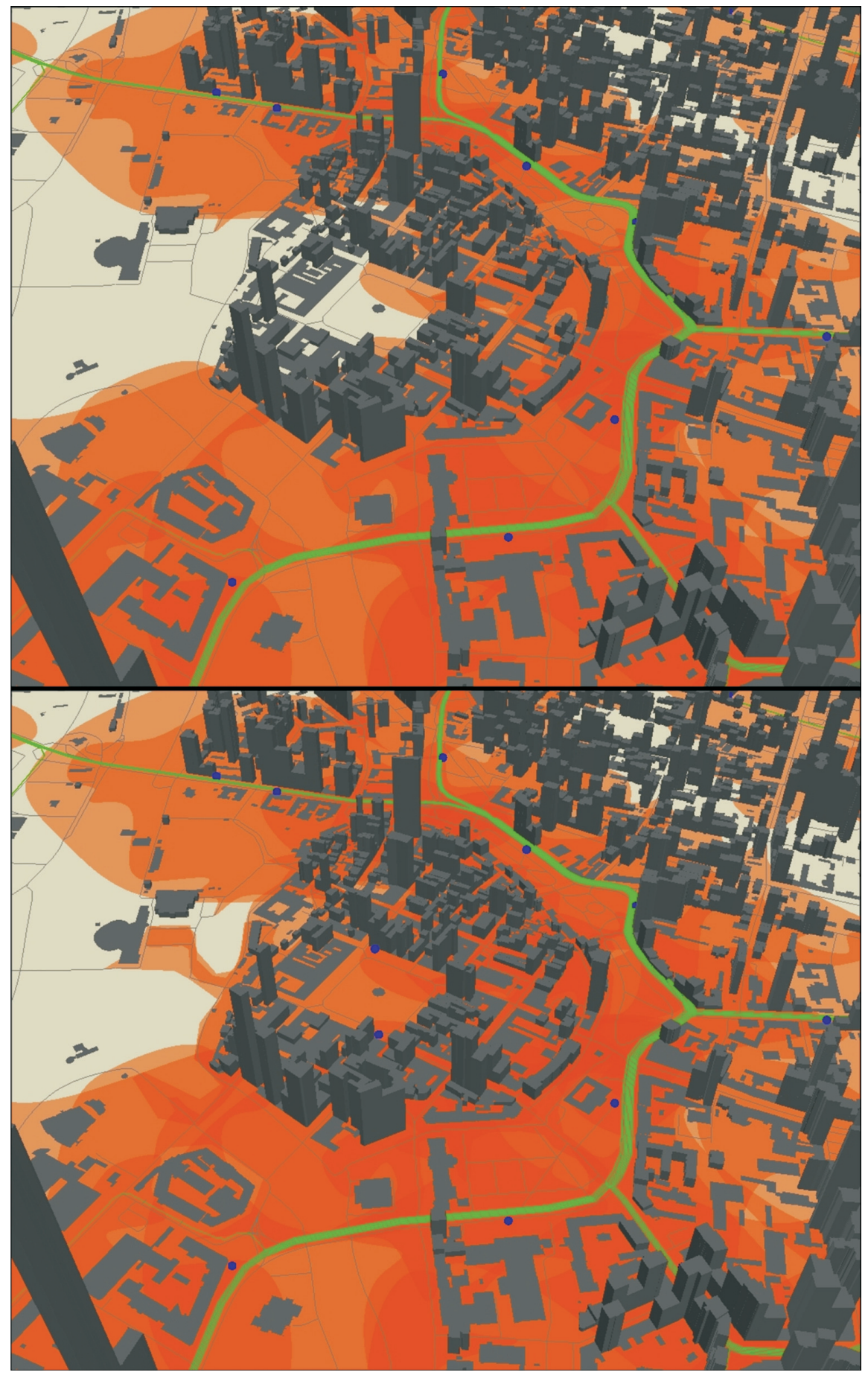

Fig. 5. Coverage of the city centre by public transport before (upper) and after (lower) the implementation of new public transport lines and stops 
layout and coverage were both very good. The evaluations found that most of the city residents lived within a $400 \mathrm{~m}$ distance from the nearest public transport stop, thus, enjoying comfortable access to the public transport lines. Both methods pointed out that the best coverage and public transport accessibility were enjoyed by the inner city and the densely populated housing estates at the outskirts. On the other hand, relatively worse characteristics were shown by the scarcely populated localities, usually also at the outskirts. This specifically points out worse stop accessibility in localities with new housing developments, to which public transport only reacts with a delay (sometimes after the residents have already got used to everyday travel by car). Second, the comparison of the two applied methods clearly shows that the buffer method provides very optimistic values which are unrealistic in detailed expression. This is because the buffer method does not respect any spatial limitations (barriers), which often exist in space. Thus, the more realistic view of public transport stop accessibility is provided by the isoline method, which fully respects these barriers.

The main indicator of the city coverage with public transport stops, with regard to their accessibility used by this research, was the data on the number of people living in the individual houses. This is a key source of information conveniently usable for the purpose of this evaluation. The number of residents represents the main attribute for decision-making about locations of individual public transport stops within the municipal system. With the help of this indicator, which is exactly geographically localised, it is possible to effectively assess the level of the city coverage with public transport stops and their accessibility zones. As this accessibility is currently more or less saturated in the city, potential establishment of new stops will not considerably change this status. On the other hand, the article points out that when assessing city coverage with public transport stops it is necessary to consider the presence of other functions of the affected municipal localities - commercial, service, work etc. - which, however, are harder to quantify. The example of establishment of new public transport stops in the centre of the city of České Budějovice was used to show that while quantitative city coverage with the stops would only provide minimal change, accessibility of key institutions located in the historic city centre would improve significantly. For effective municipal public transport system accessibility of these localities in the city is as important as accessibility of the residential areas.

This approach represents a modern view of the issue of accessibility of public transport stops in cities. Its advantages include very accurate and effective measurements and modelling of stop accessibility, which should primarily be used in transport planning. Stop accessibility is one of the key aspects affecting the competitiveness of public transport in cities. The main methodological issue is accessibility of precisely located data sources. For realistic measurements and modelling of stop accessibility it is necessary to possess information (data layers) about the distribution of residential population, the network of public transport lines, stops, pavements and other communication means for pedestrians etc. Nevertheless, this information has recently become a common part of web map services and digitalised data sources of various administrative institutions (O'SUllivan, D. et al. 2000). This is the main potential of the studied issue and the presented evaluation approaches.

Acknowledgement: The article was elaborated within the framework of the research grant project "Spatial Dynamics of Transport Relationships in the Settlement System of the Czech Republic", reg. No. 404/12/1035 sponsored by the Czech Science Foundation. 


\section{REFERENCES}

Adebola, O. and Enosko, O. 2012. Analysis of Busstops locations using Geographic Information Systems in Ibadan North L.G.A. Nigeria. Industrial Engineering Letters 2. (3): 20-37.

Ahmed, N. and Miller, H.J. 2007. Time-space transformations of geographic space for exploring, analyzing and visualizing transportation systems. Journal of Transport Geography 15. (1): 2-17. http://dx.doi. org/10.1016/j.jtrangeo.2005.11.004

BEIRÃo, G. and CABRAL, J. 2007. Understanding attitudes towards public transport and private car: A qualitative study. Transport Policy 14. (6): 478-489. http://dx.doi.org/10.1016/j.tranpol.2007.04.009

Burchell, R., Shad, N., Listokin, D. and Phillips, H. 1998. The Costs of Sprawl - Revisited. TCRP report 39. 49 p.

Cebollada, A. 2009. Mobility and labour market exclusion in the Barcelona Metropolitan Region. Journal of Transport Geography 17. (3): 226-233. http:// dx.doi.org/10.1016/j.jtrangeo.2008.07.009

Cervero, R. 2001. Walk-and-ride: factors influencing pedestrian access to transit. Journal of Public Transportation 3. (4): 1-23.

Cervero, R. and Duncan, M. (2002) Transit's ValueAdded Effects: Light and Commuter Rail Services and Commercial Land Values. Transportation Research Record: Journal of the Transportation Research Board 1805. 8-15. http://dx.doi.org/ 10.3141/1805-02

Cervero, R. and Kang, C.D. 2011. Bus rapid transit impacts on land uses and land values in Seoul, Korea. Transport Policy 18. (1): 102-116. http:// dx.doi.org/10.1016/j.tranpol.2010.06.005

Džupinová, E. 2009. Bývanie a sociálna polarizácia (príklad Bratislavy). Geographia Cassoviensis 3. (2): 55-59.

FodA, M. and Osman, A. 2010. Using GIS for Measuring TransitStopAccessibility Considering Actual Pedestrian Road Network. Journal of Public Transportation 13. (4): 23-40. http://dx.doi.org/10.1.1.399.1467

Ivan, I. 2010. Docházka na zastávku a její vliv na dojížd’ku do zaměstnání. Geografie 115. (4): 393-412.

Káčerová, M., OndačKová, J. and Mládek, J. 2014. Timespace differences of population ageing in Europe. Hungarian Geographical Bulletin 63. (2): 177-199. http:// dx.doi.org/10.15201/hungeobull.63.2.4

Kenyon, S., Lyons, G. and RAFFerty, J. 2002. Transport and social exclusion: Investigating the possibility of promoting inclusion through virtual mobility. Journal of Transport Geography 10. (3): 207-219. http:// dx.doi.org/10.1016/S0966-6923(02)00012-1
KrAfT, S. 2014. Daily spatial mobility and transport behaviour in the Czech Republic: Pilot study in the Písek and Bystřice nad Pernštejnem regions. Human Geographies - Journal of Studies and Research in Human Geography 8. (2): 51-67. http://dx.doi. org/10.5719/hgeo.2014.82.51

Langford, M. and Higgs, G. 2006.: Measuring Potential Access to Primary Healthcare Services: The Influence of Alternative Spatial Representations of Population. The Professional Geographer 58. (3): 294-306. http://dx.doi.org/10.1111/j.14679272.2006.00569.x

Mavoa, S., Witten, K., Mccreanor, T. and O'sullivan, D. 2012. GIS based destination accessibility via public transit and walking in Auckland, New Zealand. Journal of Transport Geography 20. (1): 15-22. http://dx.doi.org/10.1016/j.jtrangeo.2011.10.001

MichniaK, D. 2010. Accessibility of selected boundary regions in Slovakia. Europa XXI 20. 161-173.

Mintsis, G., Basbas, S., Papaioannou, P., Taxiltaris, C. and Tziavos, I.N. 2004. Applications of GPS technology in the land transportation system. New Technologies in Transportation Systems 152. (2): 399-409. http://dx.doi.org/10.1016/S03772217(03)00032-8

Murray, A.T. 2003. A Coverage Model for Improving Public Transit System Accessibility and Expanding Access. Annals of Operations Research 123. (1-4): 143156. http://dx.doi.org/10.1023/A:1026123329433

O'sullivan, D., Morrison, A. and Shearer, J. 2000. Using desktop GIS for the investigation of accessibility by public transport: an isochrone approach. International Journal of Geographical Information Science 14. (1): 85-104. http://dx.doi.org/10.1080/1 36588100240976

Popov, V. 2012. The culture of new mobility in Russia: Networks and flows formation. Mobilities 7. (1): 151-169. http://dx.doi.org/10.1080/17450101.2 012.631816

Sheller, M. and Urry, J. 2006. The new mobilities paradigm. Environment and Planning A 38. (2): 207-226. http://dx.doi.org/10.1068/a37268

Temelová, J., Novák, J., OuŘedníček, M. and Puldová, P. 2011. Housing Estates after Socialism: Various Trajectories and Inner Differentiation. Urban Studies 48. (9): 1811-1834. http://dx.doi.org/10.1177/00420 98010379279 


\title{
AQUINCUM Ancient landscape - ancient town
}

\author{
Edited by \\ Katalin H. Kérdố and Ferenc Schweitzer \\ Geographical Institute Research Centre for Astronomy and Earth Sciences HAS
}

Budapest, 2014. 188 p.

Geomorphological-paleoenvironmental studies supporting archeological excavations and investigations are to be considered a new trend within the broader sphere of studies on environment and geomorphology. By publishing the latest achievements of researches of this kind carried out on the territory of Aquincum and in its wider surroundings this book may equally reckon on the interest of professional circles and inquiring audience.

Therefore the publication of such a volume of somewhat unusual character is welcome. The project could be completed as a result of the close cooperation of two important branches of studies, notably geography and archeology. They both have long lasting traditions in our country and on this occasion were represented by two prominent institutions, the Geographical Institute of the Hungarian Academy of Sciences, and the Aquincum Museum of the Budapest History Museum. Their contribution has made possible the publication of this book.

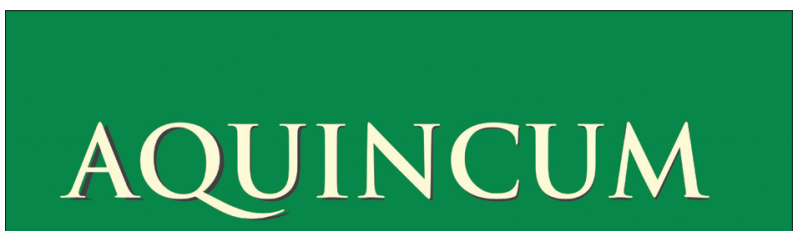

Ancient landscape - ancient town

Edited by:

Katalin H. Kérdő - Ferenc Schweitzer

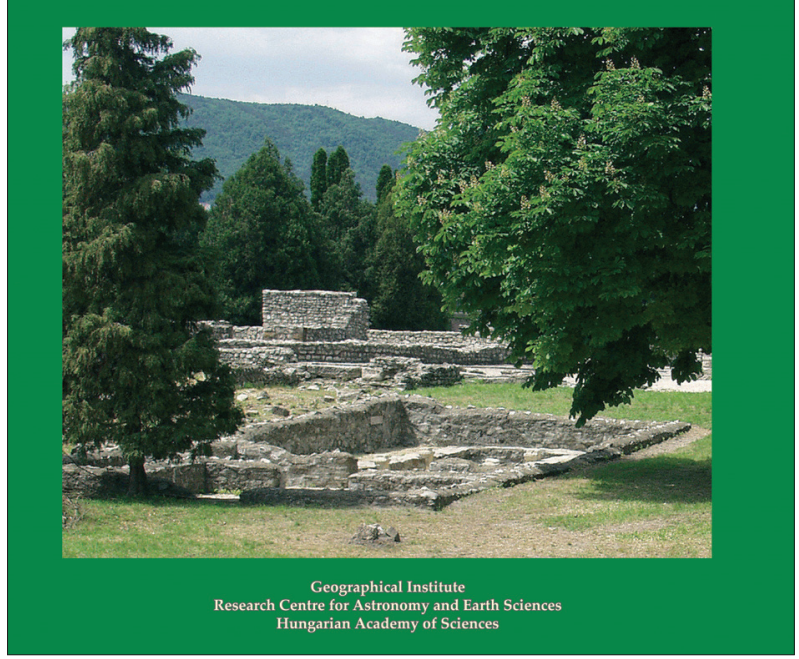

The studies were aimed to clear up the role of those natural factors which exerted a profound influence on the development of the settlement structure during the Roman Period. Romans had a special ability to realize advantages provided by geomorphological characteristics and they had made a good use of natural waters, flood-plain surface features and parent rocks for their creativity.

The volume is also deemed as a pioneering work with regard to the richly illustrated presentation of geological, geographical and other natural features exposed in several places in the course of archeological excavations. A short summary shows the most important objects of the Roman Period related to natural endowments and traces of activities of the time leading to environmental transformation.

Based on geomorphological evidence a new answer is proposed to a previously raised problem whether the Hajógyári Island existed as an islet already in the time of the Romans. Another intriguing issue tackled is the purpose of the system of trenches found in several places along the Danube River.

Price: EUR 20.00

Order: Geographical Institute of RCAES HAS.H-1112 Budapest, Budaörsi u. 44.

E-mail: magyar.arpad@csfk.mta.hu 